Report Title: $\quad$ Enhanced Practical Photosynthetic $\mathrm{CO}_{2}$ Mitigation

Type of Report: Quarterly Technical Report

Period Start: $\quad 04 / 03 / 2001$

Period End: $\quad$ 07/02/2001

Principal Authors: Dr. Gregory Kremer

Dr. David J. Bayless

Dr. Morgan Vis

Dr. Michael Prudich

Dr. Keith Cooksey, Montana State University

Dr. Jeff Muhs, Oak Ridge National Laboratories

Date Issued: $\quad$ 07/16/2001 (revision 7/25/2001)

DOE Award No.: DE-FC26-00NT40932

Organization: Ohio Coal Research Center

248 Stocker Center

Athens, OH 45701-2979

bayless@ohio.edu

(740) 5930264 voice

(740) 5930476 fax
Department of Microbiology
LW-113B
Montana State University
Bozeman, Montana 59717
umbkc@gemini.oscs.montana.edu
Division of Photonics

Oak Ridge National Laboratory

P.O. Box 2009, MS-8058

Oak Ridge, TN 32831

um4@ornl.gov

Disclaimer: $\quad$ This report was prepared as an account of work sponsored by an agency of the United States Government. Neither the United States Government nor any agency thereof, nor any of their employees, makes any warranty, expressed or implied, or assumes any legal liability or responsibility for the accuracy, completeness, or usefulness of any information, apparatus, product, or process disclosed, or represents that its use would not infringe privately owned rights. Reference herein to any specific commercial product, process, or service by trade name, trademark, manufacturer, or otherwise does not necessarily constitute or imply its endorsement, recommendation, or favoring by the United States Government or any agency thereof. The views and opinions of authors expressed herein do not necessarily state or reflect those of the United States Government or any agency thereof. 


\begin{abstract}
This quarterly report documents significant achievements in the Enhanced Practical Photosynthetic $\mathrm{CO}_{2}$ Mitigation project during the period from 4/03/2001 through 7/02/2001. Most of the achievements are milestones in our efforts to complete the tasks and subtasks that constitute the project objectives. Note that this version of the quarterly technical report is a revision to add the reports from subcontractors Montana State and Oak Ridge National Laboratories
\end{abstract}

The significant accomplishments for this quarter include:

- Development of an experimental plan and initiation of experiments to create a calibration curve that correlates algal chlorophyll levels with carbon levels (to simplify future experimental procedures)

- Completion of debugging of the slug flow reactor system, and development of a plan for testing the pressure drop of the slug flow reactor

- Design and development of a new bioreactor screen design which integrates the nutrient delivery drip system and the harvesting system

- Development of an experimental setup for testing the new integrated drip system / harvesting system

- Completion of model-scale bioreactor tests examining the effects of $\mathrm{CO}_{2}$ concentration levels and lighting levels on Nostoc 86-3 growth rates

- Completion of the construction of a larger model-scale bioreactor to improve and expand testing capabilities and initiation of tests

- Substantial progress on construction of a pilot-scale bioreactor

- Preliminary economic analysis of photobioreactor deployment

Plans for next quarter's work are included in the conclusions. A preliminary economic analysis is included as an appendix. 


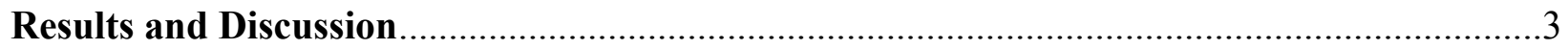

Task 1.0. Evaluate and rank component and subsystem level alternative design concepts..............3

Subtask 1.1 Investigate critical properties of alternative photosynthetic agents

(cyanobacteria) …………..............................................................................

Subtask 1.1.1 - Quantify agent growth rate characteristics in controlled experiments as a function of temperature, bicarbonate concentration, moisture content and nutrient level...........................................................

Subtask 1.1.2 - Quantify adhesion characteristics.................................................2

Subtask 1.2 - Design deep-penetration light delivery subsystem ..........................................

High-Efficiency Holographic Diffusing Element ............................................

Design and Construction of an "Illumination Rod"...........................................

Design and Construction of an "Illumination Sheet"........................................5

Subtask 1.4 - Investigate the use of a hydraulic jumps to improve the system's overall

$\mathrm{CO}_{2}$ conversion efficiency ................................................................

Subtask 1.5 - Design harvesting subsystem............................................................... 10

Subtask 1.5.1 - Examine harvesting methods for efficiency of biomass removal....10

Improving/Expanding the Experimental Facilities for Harvesting Tests..........13

Comparative Digital Image Analysis to Improve the Experimental

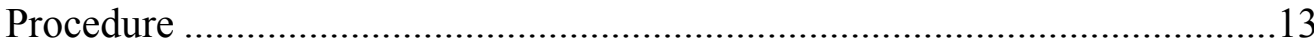

Subtask 1.6 - Quantify properties of dried biomass for potential end-uses........................15

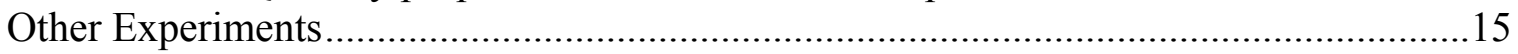

Summary of Test Run 01/17-22/01 ..........................................................15

Summary of Test Run 02/28/01-03/05/01 ………………...........................18

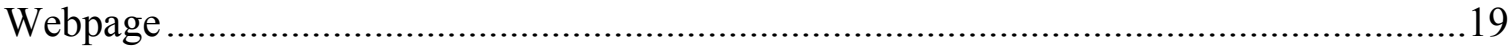

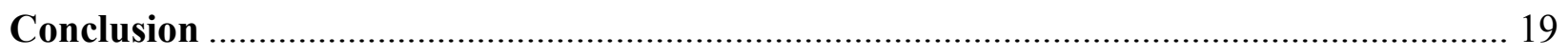

\section{Figures}

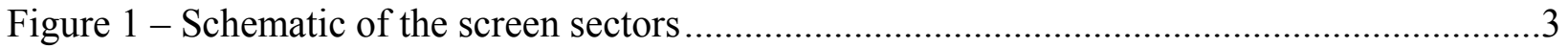

Figure 2 - 12-place tubular bioreactor for cyanobacterial growth studies …………......................

Figure 3 - The ability to colonize and the tenacity of K-Borgoria for Scotchbrite ..........................6

Figure 4 - Scanning electron microscope image (gold shadowed) of K-Borgoria on Scotchbrite 6

Figure 5a-Bioreactor screen with combined nutrient delivery drip system and harvesting

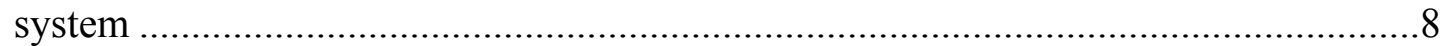

Figure $5 b$ - Side view of header pipe and separation plate. Small holes in the plate separate the pressurized area above from the fabric bundle and slot opening below to create the

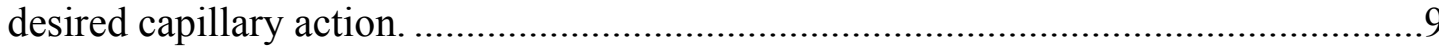

Figure 6 - Harvesting system experimental test facility............................................................

Figure 7 - Cost of one ton of $\mathrm{CO}_{2}$ removed as a function of photon conversion efficiency for a

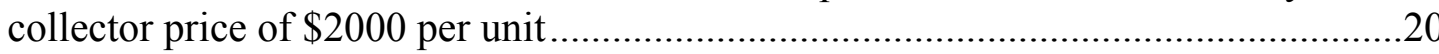

Figure 8 - Cost of one ton of $\mathrm{CO}_{2}$ removed as a function of photon conversion efficiency for a collector price of $\$ 500$ per unit 


\section{Results and Discussion}

Task 1.0. Evaluate and rank component and subsystem level alternative design concepts

Subtask 1.1 Investigate critical properties of alternative photosynthetic agents (cyanobacteria)

Subtask 1.1.1 Quantify agent growth rate characteristics in controlled experiments as a function of temperature, bicarbonate concentration, moisture content, and nutrient level.

\section{Ohio University}

Efforts on this subtask continue both at Ohio University and at Montana State. Ohio University researchers are currently focused on developing improved procedures for quantifying organism growth rates on a large scale (for example in the bioreactor) by correlating algal chlorophyll levels with carbon levels. If successful, we only have to perform chlorophyll A measurements in the future rather than a more complicated, involved method for determining primary productivity. The experimental procedure that will be followed is included below. Step 1 (testing screens for heterogeneity) is currently underway. It is expected that actual test runs will begin the week of July $16^{\text {th }}$. The Primary Productivity Protocol (PPP) is described here

1. First, we must determine any heterogeneity of algal application within and among screens

- If there exists a zonation within the screens (i.e., more algae on the top than the bottom or vice verse), document that variation

- With no vertical heterogeneity, horizontal patterns do not matter

- Using any zonation patterns, set up 4, 2x2 inch squares across the filters (see below)

- Employ three replicates up and down

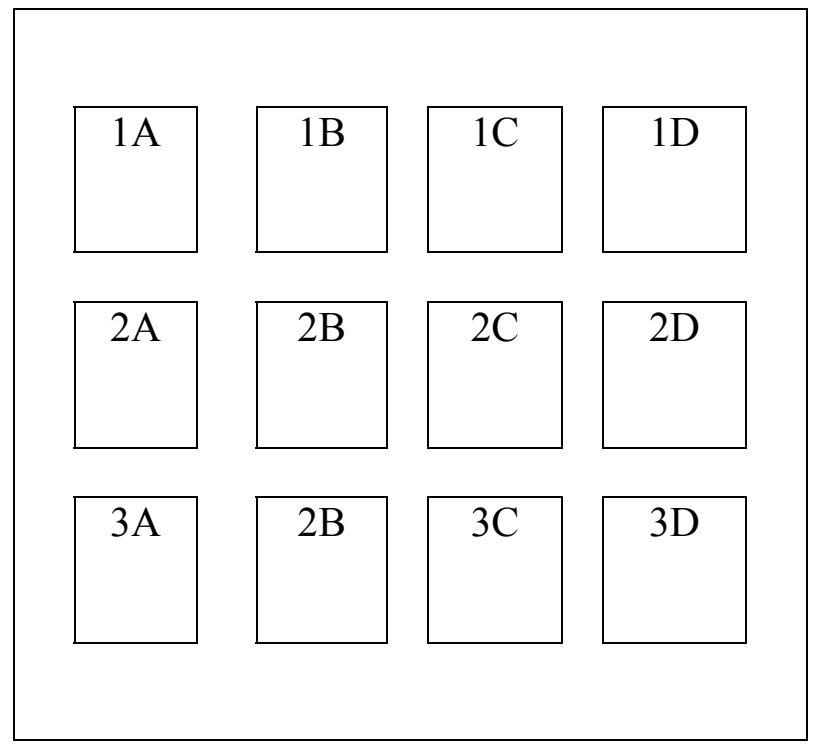

Figure 1. Schematic of the screen sectors 
2. After a full test run (3 days), cut out all pre-selected areas

- samples A and C will be subjected to acetone extraction (see below)

- samples B and D will be subjected to carbon-analysis

3. Afterwards, correlation statistics will be performed

Carbon-analysis

1. Ten non-inoculated, $2 \times 2$ inch squares will be placed in the carbon-analyzer to serve as blanks and determine variability within and between filters

2. Samples B and D from multiple filters ( 10 filters, for 60 total samples) will be dried at $50^{\circ} \mathrm{C}$ overnight and subjected to carbon analysis

Chlorophyll extraction

1. Soak each $2 \times 2$ filter piece in a cleaned test tube with $90 \% \mathrm{Mg}$-acetone solution - continue for $24 \mathrm{~h}$, with occasional agitation

2. Remove the filter, and measure the final volume of acetone

3. Filter the acetone mixture onto a $\mathrm{GF} / \mathrm{C}$ filter

4. Place disks in aluminum foil, and freeze for later use

5. Send samples to BSA Environmental services for chlorophyll a analysis

\section{From Montana State University}

Laboratory investigations. Since Yellowstone National Park was not open for foot travel until early June 2001 [snow, bear activity], we have been working with cultures provided by the University of Oregon Culture Collection [UOCC]. We found that none of those we obtained were axenic or even unialgal, but all grew at temperatures above $45^{\circ} \mathrm{C}$ and thus were potentially of use in the $\mathrm{CO}_{2}$ Remediation Facility (CRF). We have begun experiments to isolate axenic clones of these organisms. In addition we have determined conditions for optimal growth of several of these mixed cultures. In general, the cultures respond positively to additions of sodium bicarbonate, but as growth continues, this caused alkalinization of the medium and cell death. It is essential that the medium $\mathrm{pH}$ is controlled at below $\mathrm{pH}$ 9. Growth was measured as absorbance at $680 \mathrm{~nm}$ and/or as chlorophyll a content of a sample. The results obtained using these distinct measures of biomass were not different. The most promising cyanobacterial cultures from this work were Synechococcus C-1 and K-Bogoria. These are culture collection designated names for identification purposes only. No attempt to obtain 16-S derived nomenclature has been made so far. Note that K-Borgoria is actually a consortium of cyanobacteria.

Although the $\mathrm{CO}_{2}$ remediation bioreactor will house solid supports for the growth of the cyanobacterial isolates, inocula for the initial colonization of these supports will be produced in liquid cultures. To allow this and to investigate growth properties in liquid cultures, we have designed and have operating a multi tubular bioreactor in which light, temperature and $\mathrm{CO}_{2}$ supply can be controlled. There is provision for 12 replicate reactors each with a working volume of $50-100 \mathrm{~mL}$. (Figure 2) This apparatus will be used to quantify characteristics of organisms isolated from Yellowstone National Park and its environs. It has already been used to show that growth of Synechoccus C-1 becomes photo saturated at $75 \mu$ moles. $\mathrm{m}^{-2} \cdot \mathrm{sec}^{-1}$. The doubling time for this organism in the presence of $5 \% \mathrm{CO}_{2}$ in air and $5 \mathrm{mM} \mathrm{NaHCO}_{3}$ was $17 \mathrm{hr}$. Growth 
responses between tubes was excellent providing the bubbling rate was constant. No organism we have been working with grows well in the absence of fixed nitrogen in the form of nitrate.

Yellowstone National Park (YNP) and other thermal areas visited. Using a GIS data base belonging to YNP, we have identified sites within the Park where there are cyanobacteria growing at $\mathrm{pH}$ levels from $\mathrm{pH} 7-9.5$ and at temperatures from $45-65^{\circ} \mathrm{C}$. So far one of these has been visited and samples taken. These were placed in various cyanobacterial media [BG-11, Medium D and medium DH]. Microscopic assessment of the enrichments indicate that a major component of these cultures are species of Synechoccus. If these prove sensitive to the presence of the Scotchbrite polymer, it will be necessary to isolate minor components of the mixture. In order to overcome this potential problem we are trying to select only those organisms from the environment that will grow on Scotchbrite from the outset. To do this we have deployed anchored Scotchbrite coupons in thermal areas with the idea that only Scotchbrite -resistant organisms will colonize them.

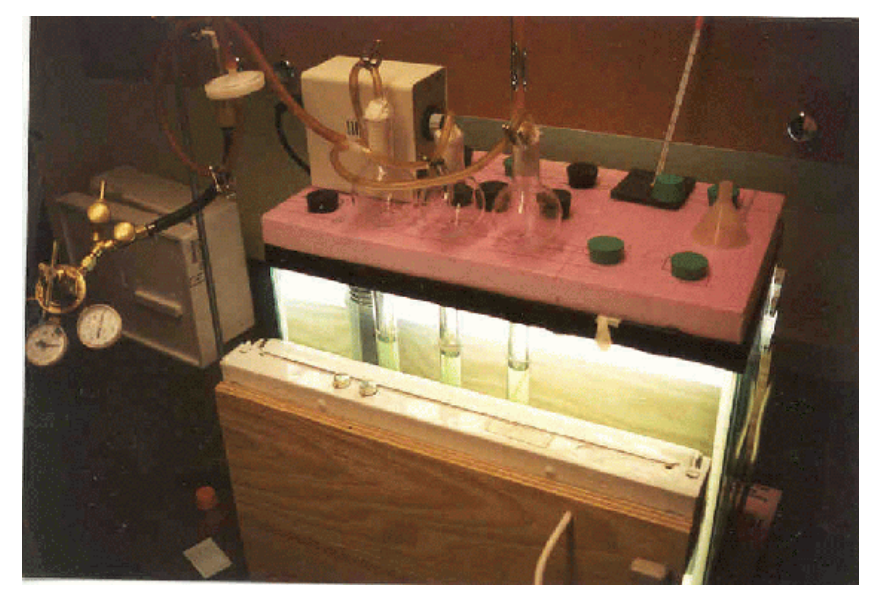

Figure 2. 12-place tubular bioreactor for cyanobacterial growth studies

\section{Sub-task 1.1.2 Quantify adhesion characteristics}

All of the above experiments have been made with organisms in liquid culture. Since the CRF will utilize a solid support for the cyanobacterial cells, we have investigated the ability of two organisms selected on the basis of their growth physiology to attach to a solid surface and form a biofilm. We used a glass surface so that quantification could be made easily by measuring surface- associated chlorophyll a. Synechoccus C-1 did not attach in three hours, but K-Borgoria reached a saturation point in two hours. This augurs well for the use of K-Borgoria in the CRF. Organisms were also offered the opportunity to attach to the surface which at the moment is a candidate for use in the CRF, i.e., the 3-M Company, Scotchbrite. This polymer, which is a nylon matrix with embedded aluminum oxide, proved toxic to two synechococcal species. Cell death occurred within a few days. On the other hand K-Borgoria grew well on Scotchbrite (Figures 3 and 4). From our relative small sample, it appears essential that an early test in assessing the usefulness of an organism in the CRF is its compatibility with the substratum to which it will be attached. The toxicity of this polymer to a cyanobacteria was not expected. We have cryo-preserved all Synechococcal species in case other less toxic substrata are proposed for use in the CR in the future. 


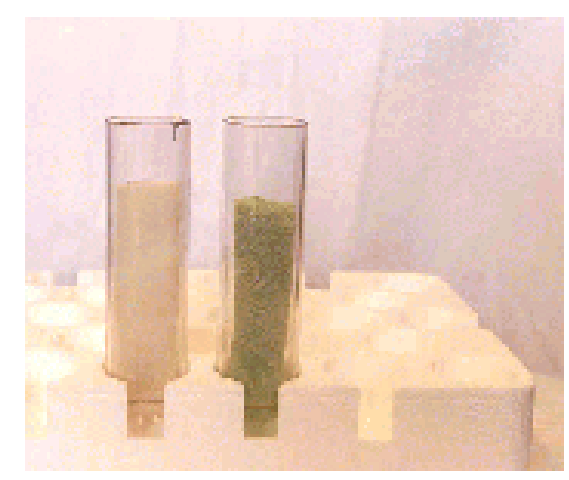

(a). Scotchbrite colonized with cyanobacteria

(b). After centrifugation

Figures 3(a) and (b) show the ability to colonize and the tenacity of K-Borgoria for Scotchbrite.

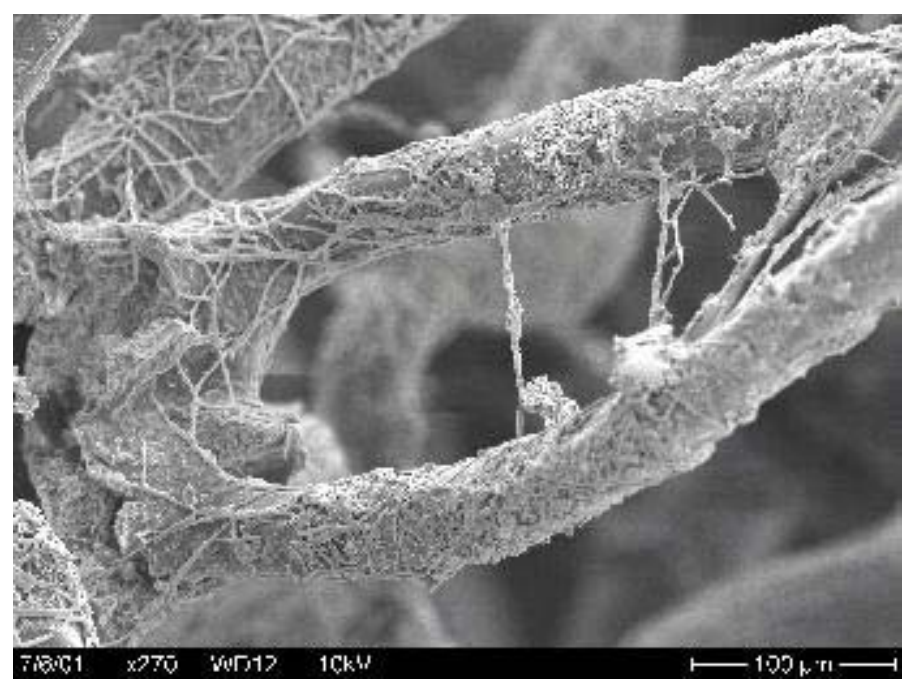

Figure 4. Scanning electron microscope image (gold shadowed) of K-Borgoria on Scotchbrite. (The fibers of the Scotchbrite are colonized with cyanobacterial cells. Magnification is 250X)

Subtask 1.2 Design deep-penetration light delivery subsystem

Work continued on the lighting system development task. ORNL began testing several solar concentrator primary mirror prototypes and two associated tracking systems. Primary mirrors being tested included a modified satellite dish with an adhesive-backed reflective film and a ground and polished glass mirror with a deposition-based enhanced aluminum coating. The surface quality of the glass mirror was found to be superior. The two tracking systems under evaluation include a sun-sensor (SS) system and a microprocessor-controlled system. The tracking accuracy of the SS tracker was found to be inadequate for our application while the microprocessor-ased system has yet to be fully evaluated. 
ORNL also fabricated a second light distribution sheet for use in the photobioreactor. The design used 3M's side-emitting optical fiber wrapped in a progressively smaller oval pattern such that the bend radius of the fiber continually decreased and the fibers became closer to one another towards the center. The unit is still under test in ORNL illumination test cell. A third design approach that reduces the amount of optical fiber and uses cylindrical fresnel lens to evenly distribute light from a center-mounted side-illuminator is also under development.

Studies were also conducted to more fully characterize the side-emitting capabilities and transmission loss of optical fibers as a function of bend radius. These tests included the use of a Cogent light source (used as a simulated sunlight source), a Prometric CCD camera (to evaluate side-illumination resulting from bends) and a large integrating sphere (to record transmission losses).

Work also continued on the evaluation of the light-carrying capacity of large-core optical fibers. This was done using a fresnel lens mounted on a two-axis solar tracker that collected sunlight and focused it onto a large-core optical fiber. The temperature of the fiber end-face was monitored using a thermocouple as the amount of collected sunlight was progressively increased. Initial results of these tests are encouraging although the data has yet to be completely analyzed.

Subtask 1.4 Investigate the use of a hydraulic jump to improve the system's overall $\mathrm{CO}_{2}$ conversion efficiency

The debugging work for the slug flow reactor has been finished, which includes checking the wiring of the transducers and flow meters and calibrating the pipeline pressure transducer, the differential pressure transducer and the orifice plate flow meter. Tests will begin as soon as test rig maintenance repairs are completed.

Considering the importance of pressure drop across the reactor, our first tests will focus on quantifying the pressure drop of the slug flow reactor and investigating how the gas and liquid velocities affect the pressure drop. The results of the pressure drop experiments will be used to optimize the gas and liquid velocities and understand the basic pressure drop of the slug flow reactor.

Once the pressure drop is understood we will begin the $\mathrm{CO}_{2}$ solubility experiments, by which we will obtain $\mathrm{CO}_{2}$ solubility as a function of operating conditions such as slug frequency, $\mathrm{CO}_{2}$ concentration additive, and $\mathrm{pH}$. An operating condition that maximizes $\mathrm{CO}_{2}$ solubility will be identified by these experiments.

The first additive that will be added to the water in order to improve the $\mathrm{CO}_{2}$ solubility is sodium hydroxide. Titration will be applied to detect the concentration of $\mathrm{OH}^{-}, \mathrm{HCO}_{3}{ }^{-}$and $\mathrm{CO}_{3}{ }^{2-}$. A carbon analyzer will be used to examine the total carbon content in the solution. 
Subtask 1.5 Design harvesting subsystem

Results from preliminary tests of water jet harvesting systems have shown that sufficient cleaning can be obtained at relatively low flow velocities and shallow incidence angles. This information has caused us to shift our focus from nozzle-based water jet harvesting methods which spray water on the growth surfaces to differential pressure water supply systems that function as both nutrient delivery drip systems (at low delivery pressures) and algae harvesting systems (at high delivery pressures). The integrated system requires a special bioreactor screen design (shown in Figure 5) which delivers moisture to the screen via capillary action under normal operation, but which creates a high flow "sheeting action" of fluid which displaces a percentage of the algae clinging to the surface when the fluid delivery pressure is increased. The experimental setup constructed to allow testing of this new design is shown in Figure 6.

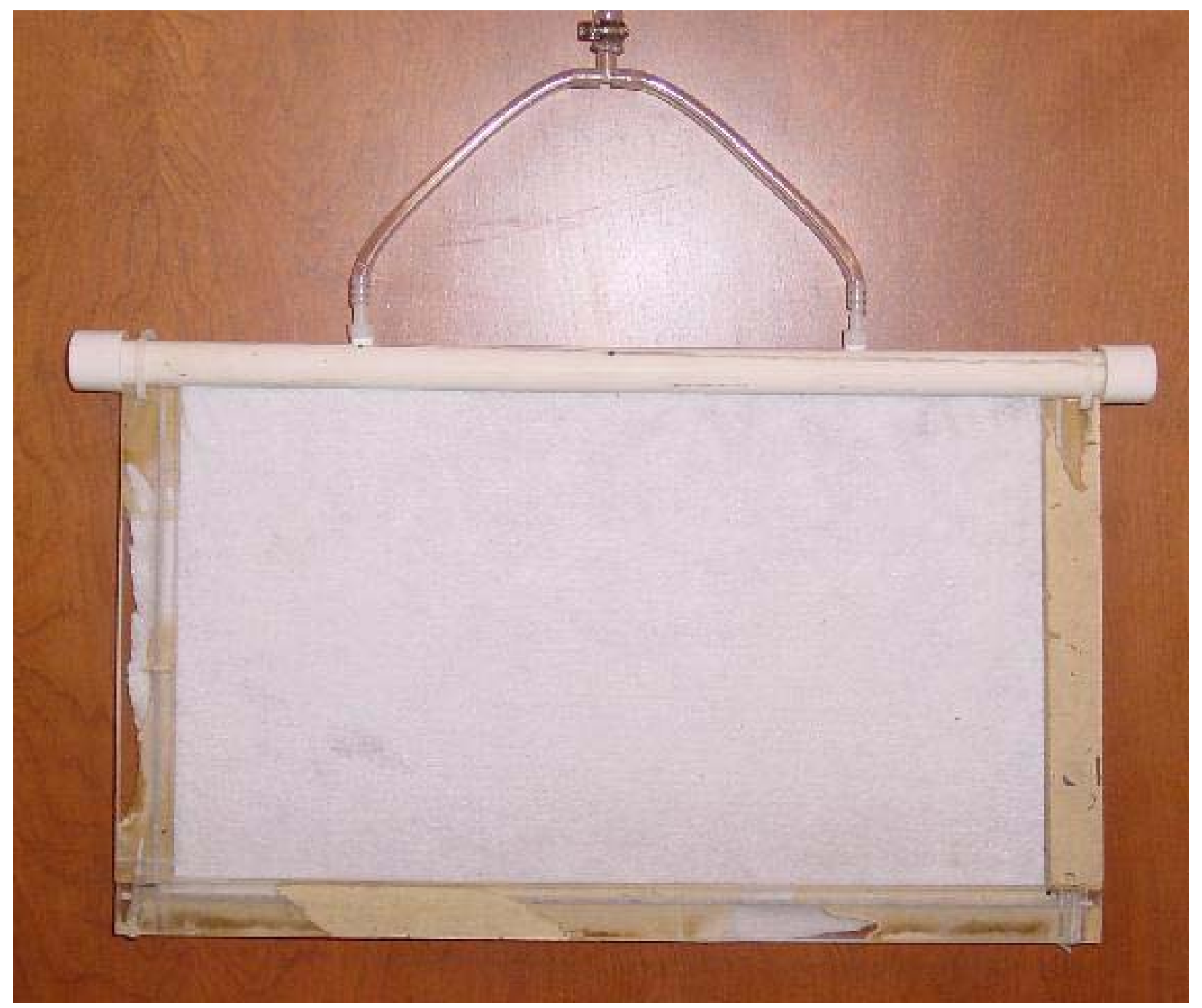

Figure 5a. Bioreactor screen with combined nutrient delivery drip system and harvesting system 


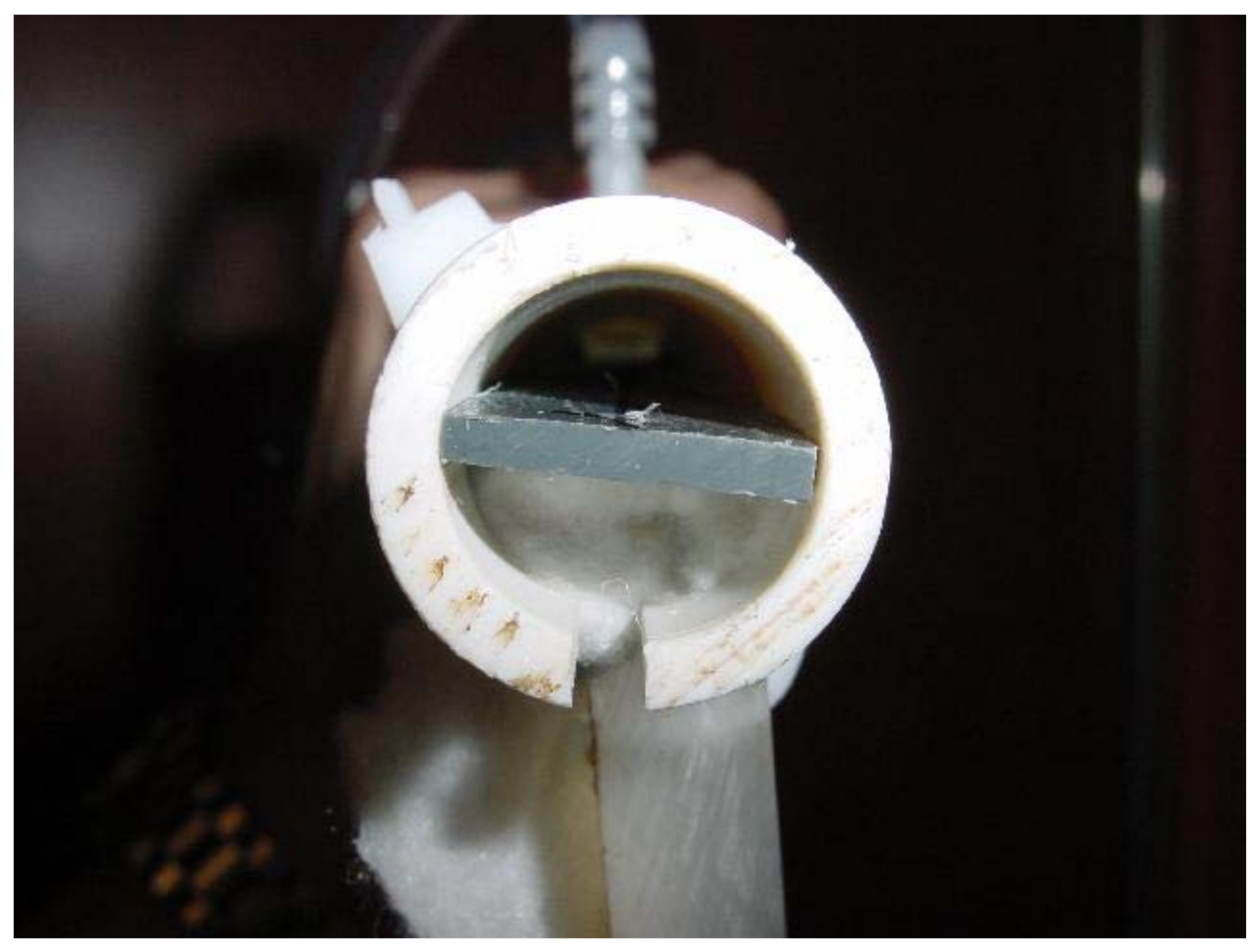

Figure $5 \mathrm{~b}$. Side view of header pipe and separation plate. Small holes in the plate separate the pressurized area above from the fabric bundle and slot opening below to create the desired capillary action.

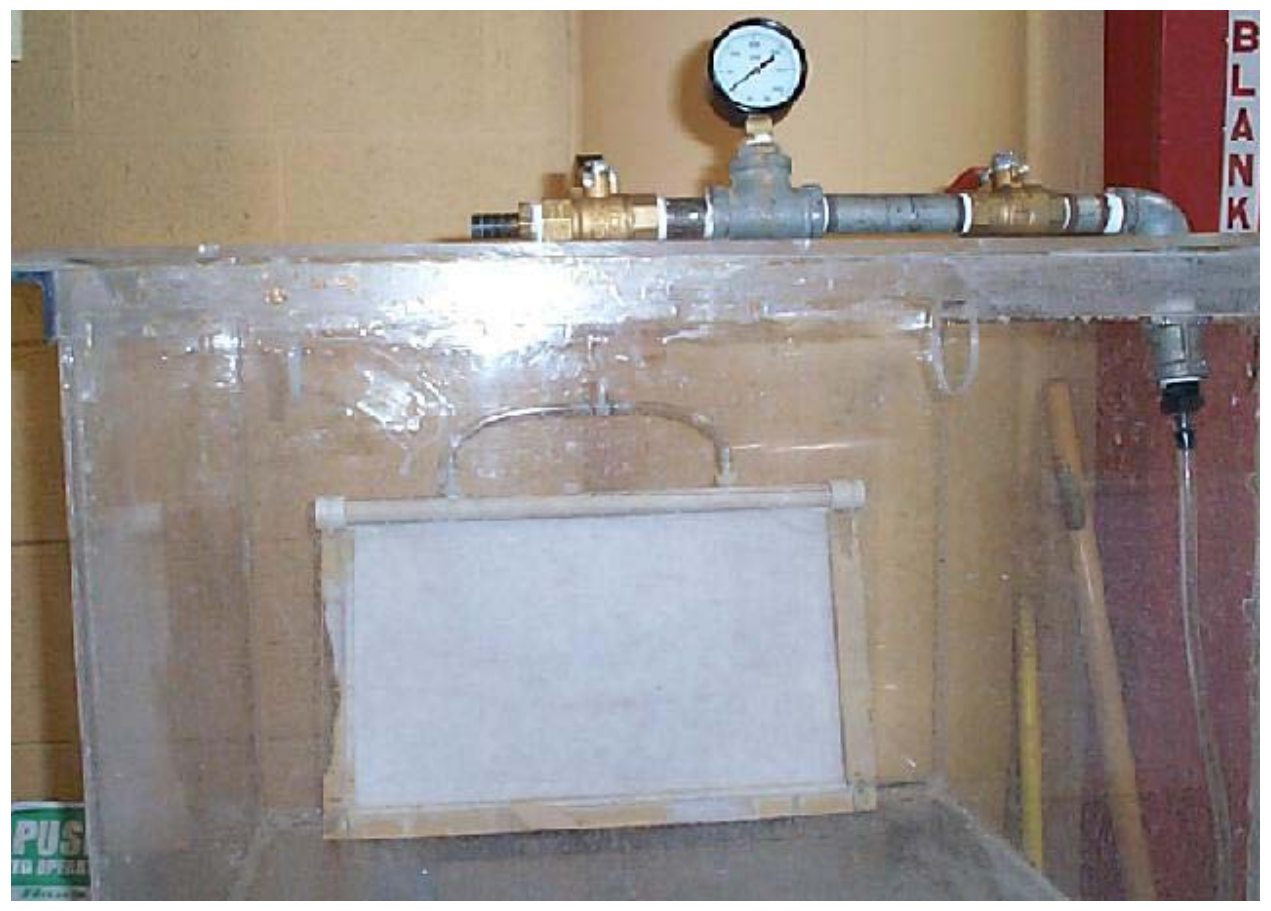

Figure 6. Harvesting system experimental test facility 
Subtask 1.5.1 Examine harvesting methods for efficiency of biomass removal

An experimental test plan is being developed for the new harvesting system design to quantify cleaning efficiency and system sensitivity to the control parameters. Recall that the goal of the harvesting system is to provide partial removal of the organisms in the cleaned area of the growth surface since total removal causes a lag in growth and $\mathrm{CO}_{2}$ uptake. Initial experiments will quantify mass percentage of algae removed as a function of supply pressure, harvesting time, etc. for a Scotch Brite growth surface fabric and Nostoc algae.

The original CRF is now available for operation as a test bed for continual harvesting system experiments. The current CRF "processing chamber" is being modified to allow extra space for the water supply pipes necessary in the new bioreactor screen design. Tests in this facility are on hold until more information is known about the performance of the new harvesting system design. Plans are to install an "optimized" version of the new combined drip/harvesting system once sufficient off-line tests have been completed.

Subtask 1.6 Quantify properties (higher heating value, elemental composition, volatile content) of dried biomass for potential end-uses.

No experimental work has been completed in this area, as current experiments are focused on identifying organisms with maximum rates of $\mathrm{CO}_{2}$ uptake in the conditions of the bioreactor.

Task 2.0. Evaluate subsystem combinations and select an "optimum" system design

Model-scale bioreactor tests in the original Carbon Recycling Facility (CRF-1) have been underway throughout the project period in an effort to develop proper experimental procedures and to accumulate system-level experience in dealing with bioreactor systems. The organisms, growth surfaces, nutrient delivery systems, etc. currently being tested have not been optimized because the subsystem level experiments are still in process. However, tests to quantify gains in algae mass as a function of light intensity levels and $\mathrm{CO}_{2}$ levels have been completed for Nostoc 86-3 cyanobacteria. Results from many of these experiments have been included in previous reports, and results from two recent light intensity test runs are summarized at the end of this section.

Two new system level experimental facilities are currently under construction, a new modelscale bioreactor and a pilot scale bioreactor. The pilot scale system is discussed in the Task 3.0 section of this report. The new model-scale bioreactor (CRF-2) is 4 times larger than CRF-1 in terms of growth surface area. Construction of CRF-2 is complete and debugging of the system is underway. Air line stability appears to be affecting the burner, so a surge volume (tank) is being added to damp out air pressure fluctuations. Also, work continues on improving the new bioreactor screen design (discussed above in the harvesting section). A new organism (cyanidium) will be tested in this bioreactor. 
The test specimen for Test Run 4.4-9.01 was the cyanobacteria, Nostoc 86-3. The target values for the gas concentrations were $3 \%, 10 \%$ and less than 50 parts per million for oxygen, carbon dioxide, and carbon monoxide, respectively, with a temperature range between $120^{\circ} \mathrm{F}-125^{\circ} \mathrm{F}$. The gas concentration averages for the 120 hours were $3.6 \%, 10.1 \%$, and 44.7 ppm for oxygen, carbon dioxide, and carbon monoxide, respectively. The 120-hour temperature average was $120.0^{\circ} \mathrm{F}$.

The lighting was not altered from Summary of Light Intensity Test for Test Run 4.4-9.01 and was cycled 12-hours on, and 12-hours off. The intensity averages for the four membranes were 68.6 $\mu \mathrm{mols} / \mathrm{s} \cdot \mathrm{m}^{2}$ for membrane-1, $72.3 \mu \mathrm{mols} / \mathrm{s} \cdot \mathrm{m}^{2}$ for membrane-2, $72.9 \mu \mathrm{mols} / \mathrm{s} \cdot \mathrm{m}^{2}$ for membrane3 , and $84.4 \mu \mathrm{mols} / \mathrm{s} \cdot \mathrm{m}^{2}$ for membrane- 4

Test Run 4.4-9.01 had a total dry algae mass gain of 1.38 grams, or a $44.4 \%$ increase over the initial estimated dry mass. The following table describes each membrane and final test results. More details are provided in Table 1.

Table 1. Data Sheet Test Run 4.4-9.01.

\begin{tabular}{|l|r|r|r|r|}
\hline Membrane Number & $\mathbf{1}$ & $\mathbf{2}$ & $\mathbf{3}$ & $\mathbf{4}$ \\
\hline Membrane Initial Dry Mass (no loading) (g) & 21.90 & 18.05 & 17.08 & 17.49 \\
\hline Membrane and Algae Final Dry Mass (g) & 22.73 & 18.89 & 18.54 & 18.58 \\
\hline Final Dry Mass of Algae (g) & 0.83 & 0.83 & 1.46 & 1.09 \\
\hline Membrane Loading Estimated Dry Mass (g) & 0.70 & 0.76 & 0.82 & 0.85 \\
\hline Mass Gain for Each Membrane (g): & 0.13 & 0.08 & 0.65 & 0.24 \\
\hline Percent Mass Gain for Each Membrane & $18.51 \%$ & $9.97 \%$ & $79.40 \%$ & $28.27 \%$ \\
\hline Mass Gain From Filter (g) & 0.07 & & & \\
Mass Gain from Beaker (g) & 0.23 & & & \\
\cline { 1 - 3 } Total Estimated Initial Dry Mass (g) & 3.12 & & & \\
\cline { 1 - 3 } Total Mass Gain (g) & 1.39 & &
\end{tabular}

\section{Uncertainty Analysis}

The uncertainty analysis is based on the results from the Algae Dry Mass Determination Test and the final results of Test Run 4.4-9.01. The average percent dry mass of the initial twelve samples was $4.46 \%$ with a standard deviation of $0.19 \%$. The same technique used to gather the twelve initial samples was used to load the membrane. An algae sample taken from the bulk tank was poured across a wire mesh to remove most of the water content, but still retaining the algae mass. The sample remained on the wire mesh for 9-minutes to further reduce water content. The remaining sample was scooped into a beaker and weighed. The algae sample in the beaker was then applied to the membrane and the beaker was weighed again to determine the algae loading weight. This was repeated for each membrane. $4.4581 \%$ of the total loading wet weight was used as the initial estimated dry mass for each membrane. 
The following sample calculation is the uncertainty at $90 \%$ confidence in the estimated initial dry mass for membrane-4. It is based on the 12-samples taken from Algae Dry Mass Determination Test, using Student's t-distribution and using four weighed samples to load each membrane.

Data from Algae Dry Mass Determination Test, Test Run 4.4-9.01 and Student's t-distribution:

Mean $=4.4581 \%$

Std. Dev $=0.1933 \%$

Degree's of freedom $=11$ (based on Student's t-distribution for 12 samples)

$\mathrm{t}_{90}=1.796$ (Student's t-distribution for 12 samples)

Uncertainty $=\frac{t \times \sigma}{\sqrt{n}}$

$\mathrm{t}=$ Student's $\mathrm{t}$-distribution for 12 samples at $90 \%$ confidence

$\sigma=$ Standard deviation of the 12 samples

$n=$ Number of samples applied to membrane- 4

Uncertainty $_{90}=\underline{1.796 \times 0.1933 \%}=0.1735 \%$

$\sqrt{4}$

Algae wet weight applied to Membrane-4 $=19.0884$ grams

Uncertainty of estimated dry weight $=19.0884 \times 0.001735= \pm 0.0331$ grams

Estimated initial dry weight $=19.0884 \times 0.044581=0.8510 \pm 0.0331$ grams

Mass gain for Membrane- $4=$ Membrane final dry weight - initial dry weight $=0.2406 \mathrm{~g}$

Uncertainty $_{90}=\frac{0.0331 g}{0.2406 g} \times 100=13.8 \%$ (uncertainty of mass gain at $90 \%$ confidence)

Table 2. Uncertainty of the mass gain for each membrane

\begin{tabular}{|c|c|c|c|c|}
\hline Uncertainty of Mass Gain & \begin{tabular}{|c|} 
Membrane- \\
1 \\
\end{tabular} & \begin{tabular}{|l|} 
Membrane- \\
2
\end{tabular} & \begin{tabular}{|c|} 
Membrane- \\
3 \\
\end{tabular} & $\begin{array}{c}\text { Membrane- } \\
4 \\
\end{array}$ \\
\hline At $90 \%$ Confidence & $21.04 \%$ & $39.04 \%$ & $4.90 \%$ & $13.77 \%$ \\
\hline At 95\% Confidence & $25.78 \%$ & $47.84 \%$ & $6.01 \%$ & $16.87 \%$ \\
\hline At 99\% Confidence & $36.37 \%$ & $67.50 \%$ & $8.48 \%$ & $23.81 \%$ \\
\hline
\end{tabular}

The second uncertainty analysis is on a total mass gain basis for the four membranes, instead of the mass gain for each membrane. The benefit of this uncertainty analysis is that the four membranes are looked at as four samples for the total mass gain, which will increase the number of samples in the uncertainty equation. All other values remain the same as in the above calculation. 
Uncertainty $_{90}=\frac{1.796 \times 0.1933 \%}{\sqrt{4}}=0.1736 \%$

Total wet weight applied to membranes $=69.9995$ grams

Uncertainty of total estimated dry weight $=69.9995 \times 0.001736= \pm 0.1215$ grams

Estimated initial dry weight $=69.9995 \times 0.044581=3.1206 \pm 0.1215$ grams

Total algae mass gain (from membranes) for test run $=1.0928$ grams

$$
\text { Uncertainty }_{90}=\frac{0.1215 g}{1.0928 g} \times 100=11.1 \% \text { (uncertainty of mass gain at } 90 \% \text { confidence) }
$$

Table 3 . Uncertainty values on a total mass basis for the four membranes combined.

\begin{tabular}{|l|r|}
\multicolumn{1}{c|}{ Uncertainty of Total Mass Gain } \\
\hline At $90 \%$ Confidence & $11.1 \%$ \\
\hline At $95 \%$ Confidence & $13.6 \%$ \\
\hline At $99 \%$ Confidence & $19.2 \%$ \\
\hline
\end{tabular}

The results conclude with $90 \%$ certainty that the mass gain of Test Run 04.4-9.01 was $1.3864 \pm$ 0.1539 grams, i.e. the mass gain was between 1.2325 grams and 1.5403 grams.

The total uncertainty associated with the scale (used for mass measurements) is estimated as a root-sum-square of the repeatability uncertainty, the resolution uncertainty, and the calibration uncertainty. The following calculation is the uncertainty at $95 \%$ confidence.

$$
\text { Uncertainty }_{95}=\sqrt{(2 \times 0.00015 g)^{2}+(0.0001 g / 2)^{2}+(0.0002 g)^{2}}= \pm 0.00036 g
$$

This would be the uncertainty for a single measurement made with this device. Since the uncertainty associated with the scale is so small, with respect to the uncertainties calculated for the mass gains, the uncertainty in the scale is neglected.

\section{Summary of Test Run 4/19-24/01}

The test specimen for Test Run 4.19-24.01 was the cyanobacteria, Nostoc 86-3. The target values for the gas concentrations were $3 \%, 10 \%$ and less than 50 parts per million for oxygen, carbon dioxide, and carbon monoxide, respectively, with a temperature range between $120^{\circ} \mathrm{F}-125^{\circ} \mathrm{F}$. The gas concentration averages for the 120 hours were $3.6 \%, 10.1 \%$, and $44.3 \mathrm{ppm}$ for oxygen, carbon dioxide, and carbon monoxide, respectively. The $120-\mathrm{hr}$ temperature average was $120^{\circ} \mathrm{F}$. 
The lighting was not altered from Summary of Light Intensity Test for Test Run 4.19-24.01 and was cycled 12-hours on, and 12-hours off. The intensity averages for the four membranes were $38.9 \mu \mathrm{mols} / \mathrm{s} \cdot \mathrm{m}^{2}$ for membrane-1, $51.5 \mu \mathrm{mols} / \mathrm{s} \cdot \mathrm{m}^{2}$ for membrane-2, $51.7 \mu \mathrm{mols} / \mathrm{s} \cdot \mathrm{m}^{2}$ for membrane-3, and $55.4 \mu \mathrm{mols} / \mathrm{s} \cdot \mathrm{m}^{2}$ for membrane- 4

Test Run 4.19-24.01 had a total dry algae mass gain of 0.3827 grams, or a $14.5 \%$ increase over the initial estimated dry mass. The following table describes each membrane and final test results. More details are provided in Table 4.

Table 4. Data Sheet Test Run 4.19-24.01.

\begin{tabular}{|l|r|r|r|r|}
\hline Membrane Number & $\mathbf{1}$ & $\mathbf{2}$ & $\mathbf{3}$ & $\mathbf{4}$ \\
\hline Membrane Initial Dry Mass (no loading) (g) & 18.93 & 24.84 & 20.75 & 24.92 \\
\hline Membrane and Algae Final Dry Mass (g) & 19.61 & 25.46 & 21.46 & 25.65 \\
\hline Final Dry Mass of Algae (g) & 0.67 & 0.62 & 0.72 & 0.73 \\
\hline Membrane Loading Estimated Dry Mass (g) & 0.66 & 0.65 & 0.68 & 0.65 \\
\hline Mass Gain for Each Membrane (g): & 0.01 & -0.02 & 0.03 & 0.08 \\
\hline Percent Mass Gain for Each Membrane & 2.13 & -3.65 & 5.00 & 12.14 \\
\hline Mass Gain From Filter (g) & 0.10 & & & \\
\hline Mass Gain from Beaker (g) & 0.18 & & & \\
Total Estimated Initial Dry Mass (g) & 2.64 & & & \\
\hline Total Mass Gain (g) & 0.38 & & &
\end{tabular}

Table 5. Uncertainty of Mass Gain for each membrane

\begin{tabular}{|c|c|c|c|c|}
\hline Uncertainty of Mass Gain & $\begin{array}{c}\text { Membrane- } \\
1\end{array}$ & $\begin{array}{l}\text { Membrane- } \\
2\end{array}$ & \begin{tabular}{|c|} 
Membrane- \\
$\mathbf{3}$ \\
\end{tabular} & $\begin{array}{c}\text { Membrane- } \\
4\end{array}$ \\
\hline At 90\% Confidence & $183.2 \%$ & $-106.8 \%$ & $77.8 \%$ & $32.1 \%$ \\
\hline At 95\% Confidence & $224.4 \%$ & $-130.8 \%$ & $95.4 \%$ & $39.3 \%$ \\
\hline At 99\% Confidence & $316.6 \%$ & $-184.5 \%$ & $134.5 \%$ & $55.5 \%$ \\
\hline
\end{tabular}

Table 6. Uncertainty values on a total mass basis for the four membranes combined.

\begin{tabular}{|l|r|}
\multicolumn{1}{|c|}{ Uncertainty of Total Mass Gain } \\
\hline At $90 \%$ Confidence & $99.5 \%$ \\
\hline At $95 \%$ Confidence & $121.9 \%$ \\
\hline At $99 \%$ Confidence & $172.0 \%$ \\
\hline
\end{tabular}

The results conclude with $90 \%$ certainty that the mass gain of Test Run 04.19-24.01 was 0.3827 \pm 0.3808 grams, i.e. the mass gain was between 0.0019 grams and 0.7635 grams. 
Task 3.0. Implement the optimum system in scaled model

The pilot scale bioreactor test facility is under construction at the Ohio University Corrosion Center. Ohio University technician Shyler Switzer is leading the construction effort and is working closely with representatives of Oak Ridge National Laboratories to ensure proper placement of the solar collectors. The current status of the pilot scale bioreactor construction is detailed below.

Group Accomplishments:

(a) Met with Tonya McFadden (Oak Ridge Intern) on 5-17-01 and brought her up to speed on the bioreactor projects.

(b) Updated a map of the Corrosion Center including the existing McBee stack, true north, and the proposed bioreactor site and emailed it to Tonya on 6-4-01 for use with their sunlight simulation program.

(c) Pictures of the proposed bioreactor site taken and emailed to Tonya on 7-5-01 to aid in the generation of the sunlight program.

(d) Met with Al Schubert from the Corrosion Center to finalize acceptance for the location of the bioreactor outside the building.

(e) Manufactured eight frames utilizing the new integrated wicking/harvesting system.

(f) Modified the harvesting test chamber on 6-27-01 for trial of the new integrated wicking/harvesting frame system.

(g) In the process of investigating alternate suppliers for a prefabricated shelter to house the bioreactor when moved to the Corrosion Center.

Tasks to Complete:

(h) Complete drawings of the Corrosion Center building addition by 7-13-01.

(i) Review final drawings with Al Schubert by 7-18-01 and break ground.

(j) Dismantle the bioreactor for relocation to the Corrosion Center.

\section{Webpage}

The web page is running at http://132.235.19.45/DOE. All parties involved in the project have received e-mail instructions and the password to access the information.

\section{Conclusions}

The activities and accomplishments detailed throughout this report indicate significant progress towards completion of project objectives. Since we have just completed the third quarter of a multi-year project, most of the test results are still preliminary and the majority of the activities underway are focused primarily on development and improvement of test facilities and procedures. Some of the most significant accomplishments this quarter include:

- Development of an experimental plan and initiation of experiments to create a calibration curve that correlates algal chlorophyll levels with carbon levels (to simplify future experimental procedures)

- Completion of debugging of the slug flow reactor system, and development of a plan for testing the pressure drop of the slug flow reactor 
- Design and development of a new bioreactor screen design which integrates the nutrient delivery drip system and the harvesting system

- Development of an experimental setup for testing the new integrated drip system / harvesting system

- Completion of model-scale bioreactor tests examining the effects of $\mathrm{CO}_{2}$ concentration levels and lighting levels on Nostoc 86-3 growth rates

- Completion of the construction of a larger model-scale bioreactor to improve and expand testing capabilities and initiation of tests

- Substantial progress on construction of a pilot-scale bioreactor

These activities and the others discussed in the report will be continued in the next quarter in support of the overall project objectives. 


\section{Appendix A - Review of Photosynthetic System Efficiency and Practicality}

There are several factors that make photosynthetic-based systems attractive for $\mathrm{CO}_{2}$ mitigation.

1. The process works well in nature.

2. Use/ recycling of $\mathrm{CO}_{2}$ is preferable to disposal.

3. Photosynthetic systems should be applicable to a variety of potential host units.

4. Multi-pollutant control, include metals and NO

5. Generation of valuable $\mathrm{O}_{2}$.

In addition, focus on development of systems to make photosynthesis a potentially viable industrial process, not organism development, allows for focus on process optimization, cost reduction, land use reduction, and ultimately can use whatever organisms may be identified as optimal in the laboratory, or even (if perfected) could deploy artificial photosynthetic reactions.

Despite such promise, there are several objections to the use of photosynthetic systems in the control of $\mathrm{CO}_{2}$ emissions. Many of these are explained well in Benemann, 1997 and are discussed here

1. Photosynthetic systems are inefficient.

True. When considering incident sunlight on rooted systems, conversion (on an energy basis) is about $1 \%$. Microalgae and cyanobacteria do better. In full sun, they do about 1$10 \%$. But there is a reason for this. At full sun, $2000 \mu \mathrm{mols} \mathrm{m} \mathrm{m}^{-2} \mathrm{~s}^{-1}$ is too great an incident photon level for the plant to process. Most organisms/plants maximize their productivities at somewhat less than $200 \mu \mathrm{mols} \mathrm{m} \mathrm{m}^{-2} \mathrm{~s}^{-1}$. When kept at low photon intensities, conversion efficiency is routinely measured over $24 \%$ with levels as high as $38 \%$ reported. (If you will note, the reactor light distribution design will keep photon levels at or below 200 $\mu \mathrm{mols} / \mathrm{m}^{-2} \mathrm{sec}$.) Also, two other external factors should be noted:

a. Even at $25 \%$ conversion, the power source is "free."

b. Research and development into reduction of antenna pigment and even chemical simulation of photosynthesis could push this efficiency higher. And while this is not in the scope of our work, such projects are underway. (I will be visiting Australia's CSIRO lab where the artificial photosynthesis research is being conducted in December.)

2. Photosynthetic systems use up too much area.

This may well be true. Photosynthetic photon flux is only $2000 \mu \mathrm{mols} \mathrm{m}^{-2} \mathrm{~s}^{-1}$ (approximately a gigawatt per $\mathrm{Km}^{2}$ ) at peak, with much lower instantaneous (and average) values being typical. However, a carefully designed system can reduce that area by increasing incident photon flux and using vertical space.

- the use of solar collector keeps PPFD at a peak by always having the collector incident with the sun

- stacking vertical organism suspension plates reduces bioreactor footprint 
Also, while it is doubtful that this process will be useful at all power generation units, most existing power plants are cited on large tracks of land, far from urban development. Most of the land at these sites is otherwise non-usable land.(except perhaps for landfill construction.) The conversion to a solar-based bioreactor would be as good a use of the land as any.

3. This process of photosynthetic carbon dioxide mitigation cost too much

At the present moment, YES. But you can say the same for every other option currently being studied. Who has a $<\$ 10$ / ton solution ready to go? It is interesting that a "natural" solution is dismissed for cost, when membrane, amine, (or whatever) separation and later land or ocean sequestration systems are just as cost prohibitive, but are widely touted as the answer to $\mathrm{CO}_{2}$ buildup.

In this section, the costs of sequestration are more closely examined, and various assumptions of process efficiency and subsystem costs are studied. The case being examined is for a powerplant with a gross capacity of $200 \mathrm{MW}$, a capacity factor of $65 \%$ operating as a load-following unit (peaking during the day when solar photons are available), with a heat rate of $9000 \mathrm{BTU} / \mathrm{kW}-\mathrm{hr}$, burning a coal containing $70 \%$ carbon by mass and a HHV of 12,000 BTU/lbm.

The bioreactor will be designed to remove $50 \%$ of all $\mathrm{CO}_{2}$ during daylight hours (during peak use), and the incident photon flux on the solar collectors as delivered to the bioreactor is $1200 \mu$ mols $\mathrm{m}^{-2} \mathrm{~s}^{-1}$. (This value assumes that the directional control of the collector surface can collect approximately $2100 \mu$ mols $\mathrm{m}^{-2} \mathrm{~s}^{-1}$ without cloud cover and the effect of weather and fiber attenuation reduces the value to 1200.)

A copy of the code used to implement the analysis based on these assumptions follows

\section{Program Code for Engineering Equation Solver}

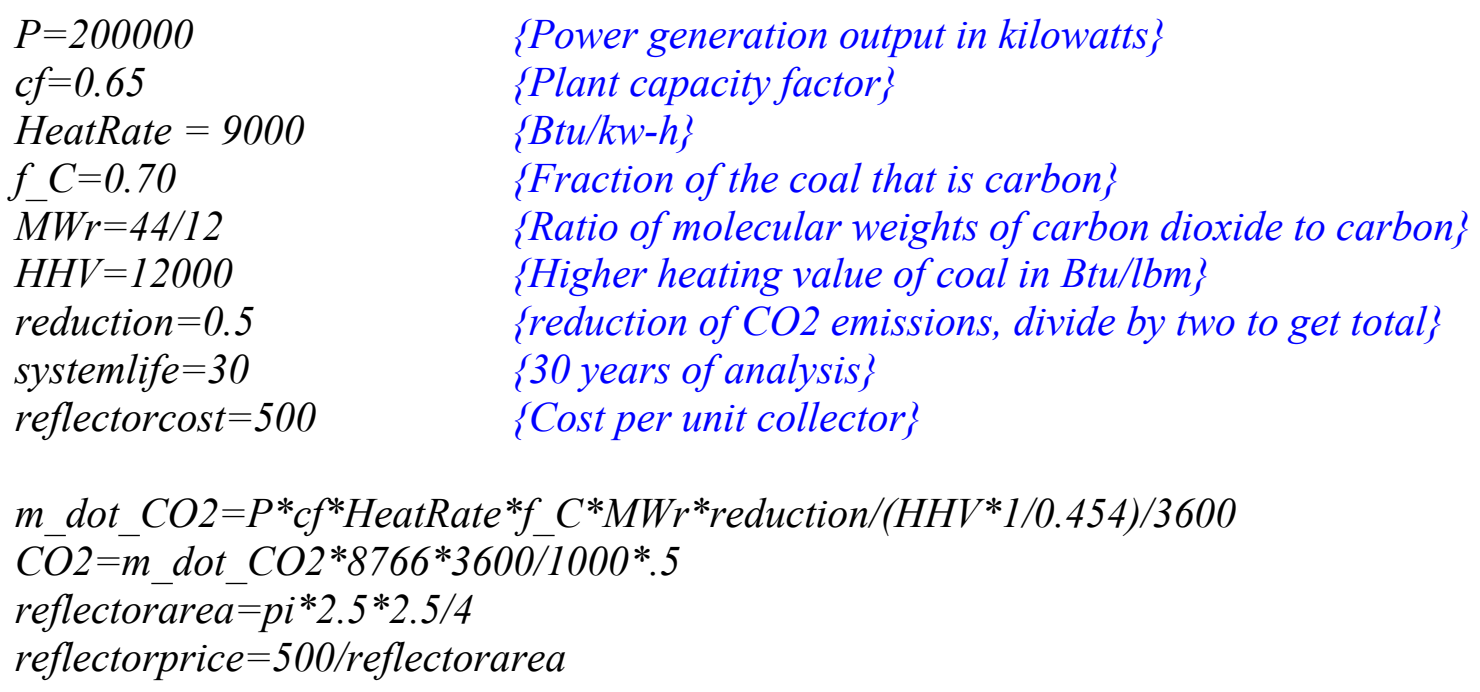


\{Lets say it takes 8 quanta (mole) of photons to convert one mole of $\mathrm{CO} 2$, then $X=8$ Absolute best efficiency you could expect of a biological agent is $X=4$

For an artificial process, the best would be about $X=2.7\}$

\author{
Mole_Co2=M_dot_co2/44 \\ photons $=1000 *$ Mole_Co $2 * X$ \\ growtharea $2=$ photons $/ 200 E-06$ \\ reactorwidth $=500$ \\ platespacing $=0.05$ \\ reactorlength $=$ growtharea $2 / 3 /$ reactorwidth/(1/platespacing) \\ collectorarea $=$ photons $/ 1200 E-06$ \\ area $2=$ collectorarea ${ }^{\wedge} .5$ \\ collectors $2=$ collectorarea \\ collectorcost $=$ collectors $2 *$ reflectorprice \\ PerTon $=$ collectorcost $/(\mathrm{CO} 2 *$ systemlife $)$
}

\title{
Analysis of Results
}

Before discussing the graphs of costs for various assumptions, it should be noted that the key cost parameter is the cost of the solar collectors. Right now, it is estimated that the collectors, built by hand, would cost $\$ 90,000$ a piece to install. Without mass production and economies of scale, $\$ 90,000$ per collector would make the cost of one ton of $\mathrm{CO}_{2}$ removed from the flue gas approximately $\$ 6000$.

However, commercialization and mass manufacture of the solar collector technology seems much more likely. The design team, headed by Oak Ridge National Laboratories, received \$3 million from DOE (DE-PS36-00GO10500) to further their hybrid lighting work. Their technology, while extremely useful (if not absolutely necessary) for the bioreactor, is actually focused towards use as a lighting system in commercial buildings. More information on their program related to development can be found at http://www.ornl.gov/hybridlighting/.

In order to examine the effect of photon conversion efficiency at a collector cost of $\$ 2000$ per unit, Figure 1 was generated. Using the previously stated assumptions, the minimum cost for collection of one ton of $\mathrm{CO}_{2}$ over the lifetime of the bioreactor, assuming continuous use with the unit, would be $\$ 44$, with a more likely cost (assuming an optimistic 30\% conversion efficiency) is $\$ 146$ per ton.

At $\$ 500$ per collector, the costs are more reasonable, as shown in Figure 2. Using the same assumptions used to generate Figure 2, except for the $\$ 500$ per collector cost, the cost of removing one ton of $\mathrm{CO}_{2}$ over the life of the bioreactor falls to a minimum of $\$ 11$ and a more likely value of $\$ 37$ per ton. 


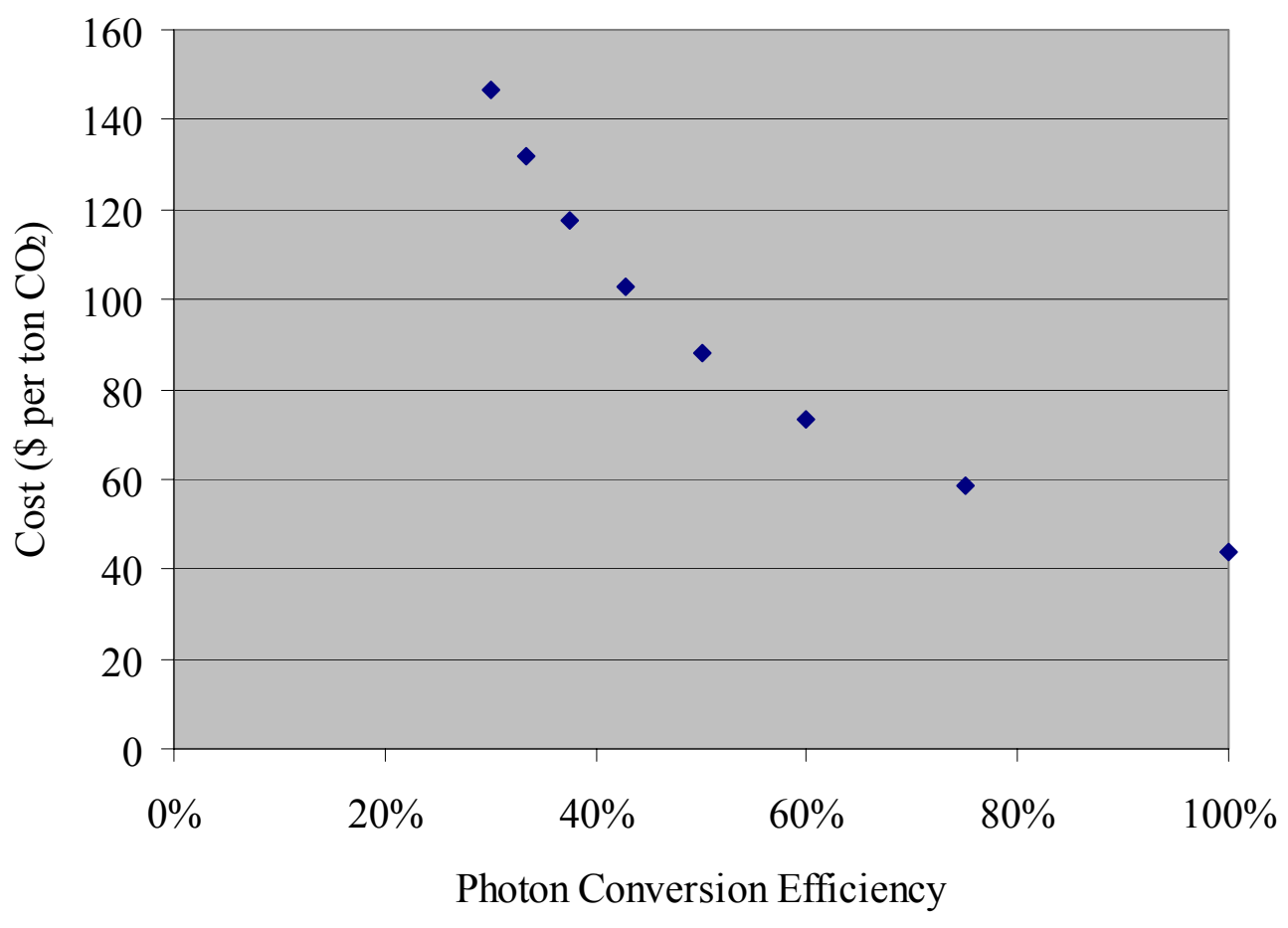

Figure 7. Cost of one ton of $\mathrm{CO}_{2}$ removed as a function of photon conversion efficiency for a collector price of $\$ 2000$ per unit.

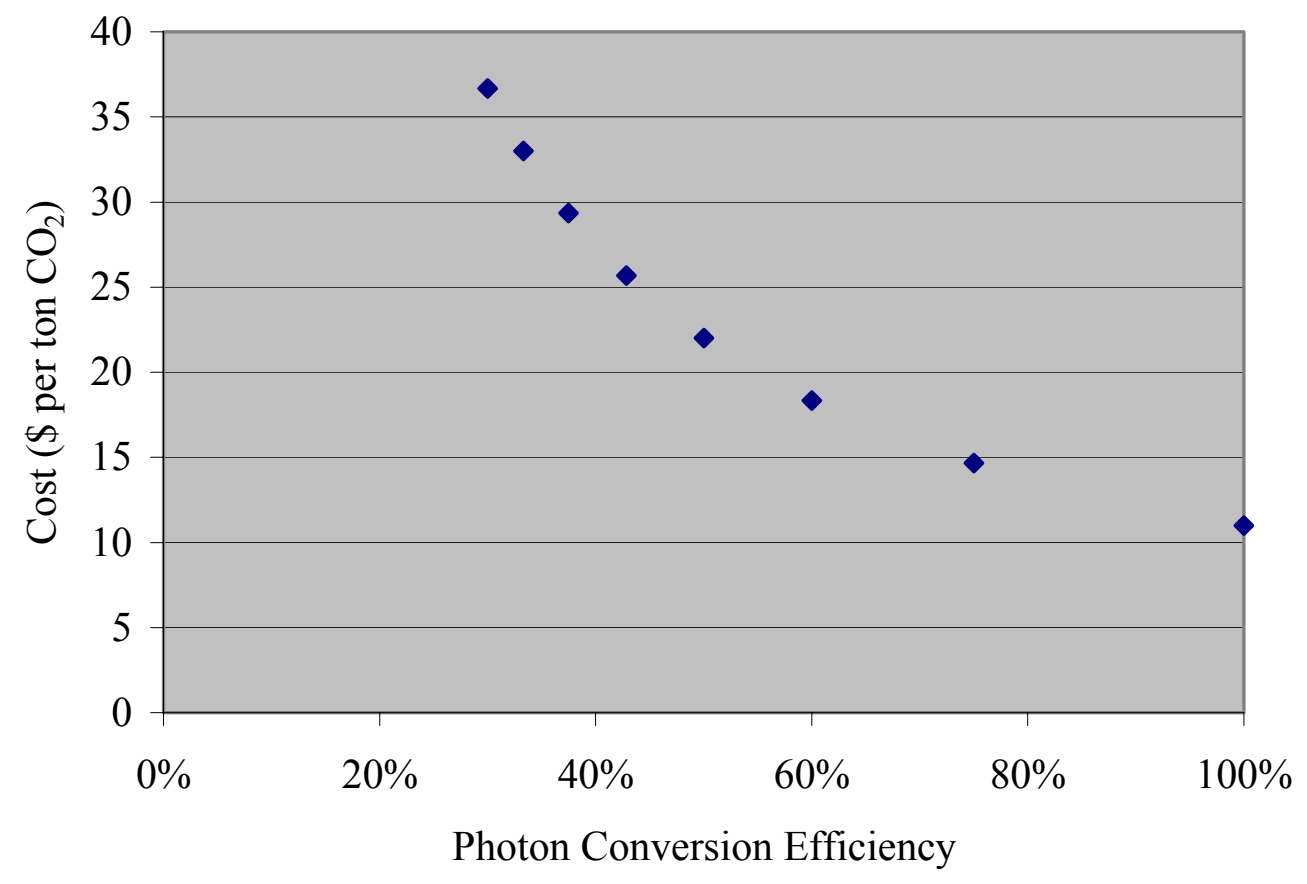

Figure 8. Cost of one ton of $\mathrm{CO}_{2}$ removed as a function of photon conversion efficiency for a collector price of $\$ 500$ per unit. 
If line losses (photon attenuation) is reduced and deployment of such a unit occurs in a "sunnier" location, the incident photon level could increase to approximately $1500 \mu \mathrm{mols}$ $\mathrm{m}^{-2} \mathrm{~s}^{-1}$, the cost of $\mathrm{CO}_{2}$ removal (per ton) at a conversion efficiency of $30 \%$ is $\$ 29$.

While not all the analysis done on economics is presented here (it will be given in the final report), it is clear that current system design, even if deployed in "sunny" locations, will require a more efficient organism or process to carry out photosynthesis. It is important to note that the target economics, as described in the proposal (\$8-\$10 per ton), would require $50 \%$ conversion efficiency and a collector cost of $\$ 250$ per unit.

\section{Value of Byproduct (biomass)}

Of course, another key parameter, and the one sought after by many proponents of photosynthetic control, is the value of the harvested biomass. It is well accepted that biomass could be used in a number of applications, including
- fertilizer $\bullet \mathrm{H}_{2}$ source
- animal feed stock
- biodiesel
- pigment/ dyes
- Dietary supplement(beta carotene)

Work has not yet been done under this program to investigate other potential uses of the biomass. However, any positive revenue (or offsetting cost) of the biomass would positively influence the overall economics.

This aspect will also be discussed in more detail in the final report. 